\title{
СМЫСЛОВЫЕ АСПЕКТЫ ТЕЛЕСНОГО ОПЫТА ХРОНИЧЕСКОГО СОМАТИЧЕСКОГО ЗАБОЛЕВАНИЯ
}

\author{
(С) Василенко Т.Д., Селин А.В., Мангушев Ф.Ю.
}

Курский государственный медицинский университет, Курск

E-mail: tvasilenko@yandex.ru

\begin{abstract}
В статье представлены результаты исследования внутреннего телесного опыта при хроническом соматическом заболевании, а также отражена взаимосвязь телесности и смыслового аспекта личности на моделях здоровья и хронических соматических заболеваний. Выявлено, что телесный опыт хронического соматического заболевания связан с изменениями смысловой сферы личности и выражается в преобладании негативной оценки прошлого, настоящего и будущего, снижении значимости постановки жизненных целей. Наличие специфических симптомов заболевания, сопровождающихся телесными ощущениями, влияет на интеграцию нового телесного опыта в Я-структуру, формируя специфическое восприятие своего тела. Выделены факторы дезадаптивного реагирования личности на заболевание: рефлексивность, локус контроля. Дезадаптивная взаимосвязь телесности и смыслового аспекта личности обусловлена блокированием рефлексивных процессов и повышением экстернализации уровня локуса контроля.
\end{abstract}

Ключевые слова: телесность, телесный опыт хронического соматического заболевания, смысловая сфера личности, рефлексивность, стресс, дезадаптивная реакция, локус контроля, качество жизни.

\section{SEMANTIC ASPECTS OF CORPORAL EXPERIENCE IN A CHRONIC SOMATIC DISEASE Vasilenko T.D., Selin A.V., Mangushev F.Yu. Kursk State Medical University, Kursk}

The article presents the results of studying inner body experience in people with chronic somatic diseases, and the correlation between body experience and semantic sphere of personality based on models of health and chronic somatic disease. Body experience of a chronic somatic disease correlates with value-semantic variations that manifests in dominant negative evaluation of the past, present and future, de-emphasis of life goal-setting. The presence of morbid specific symptoms accompanied with physical sensations influences the integration of a new body experience into self-concept creating a specific perception of the body. The factors of person's maladaptive reactions on a disease such as reflexivity, locus of control are marked out. Maladaptive correlation between body experience and semantic component of personality is conditioned by blocking reflexive processes and increaseing externalization of control locus level.

Keywords: corporeity, body experience of a chronic somatic disease, semantic personality sphere, reflexivity, stress, maladaptive reaction, locus of control, life quality.

Актуальность проблемы определяется наличием в социально-демографической структуре общества значительного количества лиц, находящихся в ситуации хронического заболевания, что подтверждается данными ВОЗ. Хронические заболевания имеют высокое распространение независимо от возраста и региона. К наиболее распространенным хроническим заболеваниям относятся: ишемическая болезнь сердца, сахарный диабет и хронические заболевания дыхательных путей [14]. Ситуация хронического соматического заболевания описывается как провоцирующая кризис психического развития в целом и развития личности, в частности [5]. Объективная ситуация тяжелого, опасного соматического заболевания, отрыв от привычного социального окружения, опасность ухудшения соматического состояния приводят к изменению объективного положения человека в социальной среде. Суть патогенного воздействия болезни на личность заключается в том, что массивная и длительная интоксикация, нарушение обменных процессов, истощение приводят к изменению протекания психических процессов, к снижению операциональнотехнических возможностей пациентов. Центральным психологическим механизмом личностных изменений в условиях хронической соматической болезни выступает перестройка иерархии мотивов по типу их переподчинения новому главному смыслообразующему мотиву сохранения жизни и восстановления здоровья. Кроме того, снижается уровень опосредованности деятельности в сторону ее упрощения, происходит сужение основного круга отношений человека с миром, т.е. сужение интересов, обеднение мотивационной сферы, что выражается в изменении привычного уклада жизни [12].

При прогрессировании хронической болезни меняется вся система отношений больных. Значимыми становятся только те события, которые не противоречат вновь выделившемуся смыслообразующему мотиву сохранения жизни. Вследствие этого появляется замкнутость, 
отчужденность, обеднение контактов с людьми, пассивность. Выделение мотива сохранения жизни ведет к формированию ограничительного поведения: инертности, снижению активности [9].

Особенностью нарушения психической адаптации в ситуациях, являющихся необратимыми, в которых действие завершено, и событие невозможно изменить, таких как хроническое заболевание, является возможность формирования состояния безысходности, усталости, горя, подавленности и угнетенности, раздумья, тревоги, депрессии и неприязни [10]. Подобные состояния, характеризующиеся большой длительностью, влияют как на процесс формирования стратегий совладания с ситуацией, так и на способность формирования адекватных стратегий поведения.

Ситуация хронического заболевания, особенно обладающего характеристиками высокой опасности для благополучия, выступает как кризисная жизненная ситуация [5]. Телесный опыт в этой ситуации переживается личностью в контексте всего жизненного пути, при этом взаимосвязь телесного и психического дополняется более сложными процессами, помещается в систему отношений личности к собственной жизни и оказывается связанной со смыслом жизни. В результате происходит изменение самой картины жизненного пути и идентичности личности в контексте ее жизненных планов, замыслов, осуществления ролей. Интеграция телесного опыта может носить дезадаптивный характер и приводить к изменению смысловых аспектов структуры субъективной картины жизненного пути [4].

Само по себе хроническое заболевание приводит к изменению биологических условий функционирования человека в виде снижения операциональных и энергетических возможностей деятельности. Вместе с тем, благодаря когнитивной оценке, переработке биологического, телесное начинает включаться в собственно психологическую регуляцию, формируется смысл болезни, который может носить преградный, позитивный или конфликтный характер [1]. Факт заболевания проявляется изначально в сфере телесных ощущений, которые сопутствуют заболеванию и сигнализируют человеку о его возникновении, включаются механизмы когнитивной переработки, происходит означивание телесных ощущений, из которых формируется симптом болезни. Осуществляется когнитивная оценка означенных ощущений, насколько сильно они влияют на актуальную жизненную ситуацию, на способность собственной реализации, таким образом формируя представление о возможностях своего телесного Я; необходимым для этого фактором является рефлексия как интегративный процесс. Рефлексивность обеспечивает непосредственный самоконтроль поведения человека в актуальной ситуации, осмысление ее элементов, анализ происходящего, способность субъекта к соотнесению своих действий с ситуацией и их координации в соответствии с изменяющимися условиями и собственным состоянием [6]. Важную роль в процессе осмысления имеет представление о детерминированности актуальных событий и роли личности в них, что выражается в большей интернальности или экстернальности локуса контроля. Человек осознает, что он болен, определяет свое отношение к этому факту и понимает, какие последствия это может нести для него. Больной концентрируется на факте заболевания, отодвигая на задний план все остальные сферы отношений и деятельности, что может отразиться на смысловой сфере в виде снижения общей осмысленности жизни, негативной оценки как актуальной ситуации, так и пройденного жизненного пути. Поскольку болезнь хронически текущая, а значит, длительная, человек вынужден изменять свою деятельность, появляются новые формы деятельности (лечение, диета, физическая культура и т.д.). Вследствие этого возможно изменение смыслов, привычных для личности форм деятельности. Факт болезни, опосредуясь в системе смыслов, начинает изменять всю смысловую сферу личности; человек может сосредоточиваться на факте заболевания, что приводит к уменьшению веса других смыслов и деятельностей в его жизни (сужение сферы интересов и мотивов). Таким образом, происходит процесс взаимодействия связанного с возникновением заболевания телесного опыта и смыслового компонента личности. В роли процессов-интеграторов, факторов взаимодействия телесного опыта и смысловой сферы выступают снижение или чрезмерное повышение рефлексивности как процесса непосредственного самоконтроля поведения человека в актуальной ситуации, а также направленность субъективного контроля в сторону снижения ощущения способности влиять на актуальную ситуацию, или чрезмерная уверенность в возможности контроля всех жизненных аспектов, что может приводить к дезадаптивным реакциям [3, 4].

Наше исследование направлено на изучение смыслового аспекта телесного опыта хронического соматического заболевания, а также на выявление факторов дезадаптивного реагирования на телесный опыт. 


\section{МАТЕРИАЛЫ И МЕТОДЫ ИССЛЕДОВАНИЯ}

Исследование осуществлялось на базах ОБУЗ «Курская горбольница № 3», ОБУЗ «Курский областной клинический кожно-венерологический диспансер», ОБУЗ «Курская городская клиническая больница скорой медицинской помощи». Общий объем выборки составил 168 человек. Формирование экспериментальных групп осуществлялось по критерию нозологической принадлежности: испытуемые с диагнозом ишемическая болезнь сердца (ИБС) (13 мужчин, 15 женщин, средний возраст 46 лет); испытуемые с бронхиальной астмой (18 мужчин, 25 женщин, средний возраст 41 год); испытуемые с диагнозом диабет (2-го типа) (22 мужчины, 25 женщин, средний возраст 45 лет). В исследование была включена контрольная группа в составе 50 человек (25 женщин, 25 мужчин, средний возраст 43 года), не предъявляющих жалоб на состояние здоровья. Обследование осуществлялось на условии информированного согласия в индивидуальной форме.

Методы исследования: клиническое наблюдение, архивный метод (работа с медицинскими картами больных), психодиагностические методики (методика «Выбор дескрипторов интрацептивных ощущений» (ВДИО) А.Ш. Тхостова; методика исследования ценностно-смысловой сферы «Тест смысложизненных ориентаций» (СЖО) Дж. Крамбо и Л. Махолика в адаптации Д.А. Леонтьева [7]; опросник саморефлексии телесного потенциала Г.В. Ложкина, А.Ю. Рождественского [8]; методика диагностики уровня развития рефлексивности опросник А.B. Карпова [6]; опросник BIQLI (влияние образа тела на качество жизни) Томас Ф. Кэш [2]; опросник «Уровень субъективного контроля» Е.Ф. Бажина, Е.А. Голынкиной, Л.М. Эткинда) [11], методы математической статистики (статистическая обработка проводилась при помощи Statistica 6.0, с использованием методов описательной и сравнительной статистики (непараметрический U-критерий Манна-Уитни)).

\section{РЕЗУЛЬТАТЫ ИССЛЕДОВАНИЯ И ИХ ОБСУЖДЕНИЕ}

В результате изменения интрацептивных ощущений, связанных с соматическим заболеванием, наиболее ярко проявляется феномен телесной осознанности как компонент структуры самосознания личности. Исследование этого аспекта включало рассмотрение особенностей дескрипторов интрацептивных ощущений у людей с хроническими соматическими заболеваниями в сравнении со здоровыми.

В результате исследования дескрипторов интрацептивных ощущений было выявлено, что в группах с соматическими заболеваниями дескрипторы чаще относятся к таким категориям, как: часто испытываемые ощущения, важные ощущения, опасные ощущения, что связано с расширением телесного опыта, вызванного сопровождающими заболевания ощущениями (табл. 1).

Стоит отметить, что в группах с ИБС и бронхиальной астмой к категории опасных относят значительно большее количество дескрипторов по сравнению с испытуемыми с диабетом. Статистически значимые различия по параметру «болезненные ощущения» были получены в группе с ишемической болезнью сердца, дескрипторы, отнесенные в эту группу, носят характер высокой интенсивности. Уровень саморефлексии телесного потенциала в группах исследуемых с ИБС и бронхиальной астмой значительно ниже, чем в группе здоровых и больных диабетом. В этих группах преобладают явные значения просоциального типа, граничащего с витальным, и витальный тип саморефлексии. В то время как в контрольной группе значения находятся на среднем уровне просоциального типа. Тело воспринимается в большей степени как инструмент, ценностный статус которого ограничивается задачей соответствия существующим представлениям, с одной стороны, и возможностями, ограниченными соматическим заболеванием - с другой.

Таблица 1

Показатели значимости различий дескрипторов интрацептивных ощущений больных хроническими соматическими заболеваниями

\begin{tabular}{|c|c|c|c|c|c|c|c|}
\hline \multirow{3}{*}{ Показатель } & \multirow{3}{*}{$\begin{array}{c}\begin{array}{c}\text { Контрольная } \\
\text { группа } \\
\text { (здоровые) }\end{array} \\
\bar{x}\end{array}$} & \multicolumn{6}{|c|}{ Группы исследования } \\
\hline & & \multicolumn{2}{|c|}{$\begin{array}{c}\text { ишемическая } \\
\text { болезнь сердца }\end{array}$} & \multicolumn{2}{|c|}{$\begin{array}{c}\text { бронхиальная } \\
\text { астма }\end{array}$} & \multicolumn{2}{|c|}{ диабет } \\
\hline & & p-level & $x$ & p-level & $\bar{x}$ & p-level & $\bar{x}$ \\
\hline Часто испытываемые ощущения & 4,57 & $0,001 * *$ & 12,3 & $0,014 *$ & 5,62 & $0,041 *$ & 4,00 \\
\hline Важные ощущения & 3,49 & $0,000 * *$ & 7,00 & $0,027 *$ & 6,91 & 0,253 & 3,74 \\
\hline Опасные ощущения & 4,89 & $0,002 * *$ & 12,5 & $0,032 *$ & 6,07 & $0,044 *$ & 5,14 \\
\hline Болезненные ощущения & 8,87 & $0,000 * *$ & 15,3 & 0,278 & 10,7 & 0,817 & 9,18 \\
\hline Саморефлексия телесного потенциала & 4,46 & $0,007 * *$ & 3,03 & $0,034 *$ & 3,91 & 0,545 & 4,51 \\
\hline
\end{tabular}

Примечание: * $-\mathrm{p}<0,05 ; * *-\mathrm{p}<0,01$. 


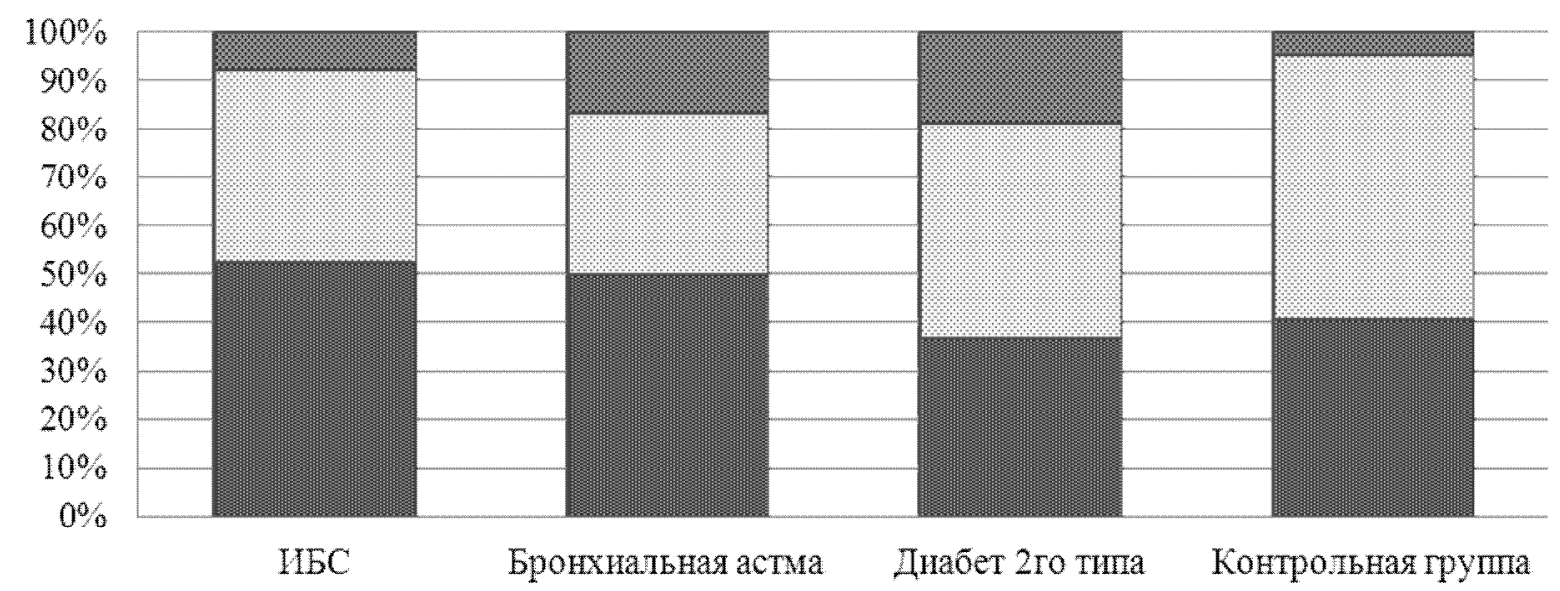

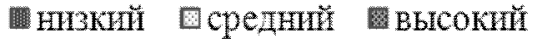

Рис. 1. Уровень рефлексивности в группах исследования и контрольной группе.

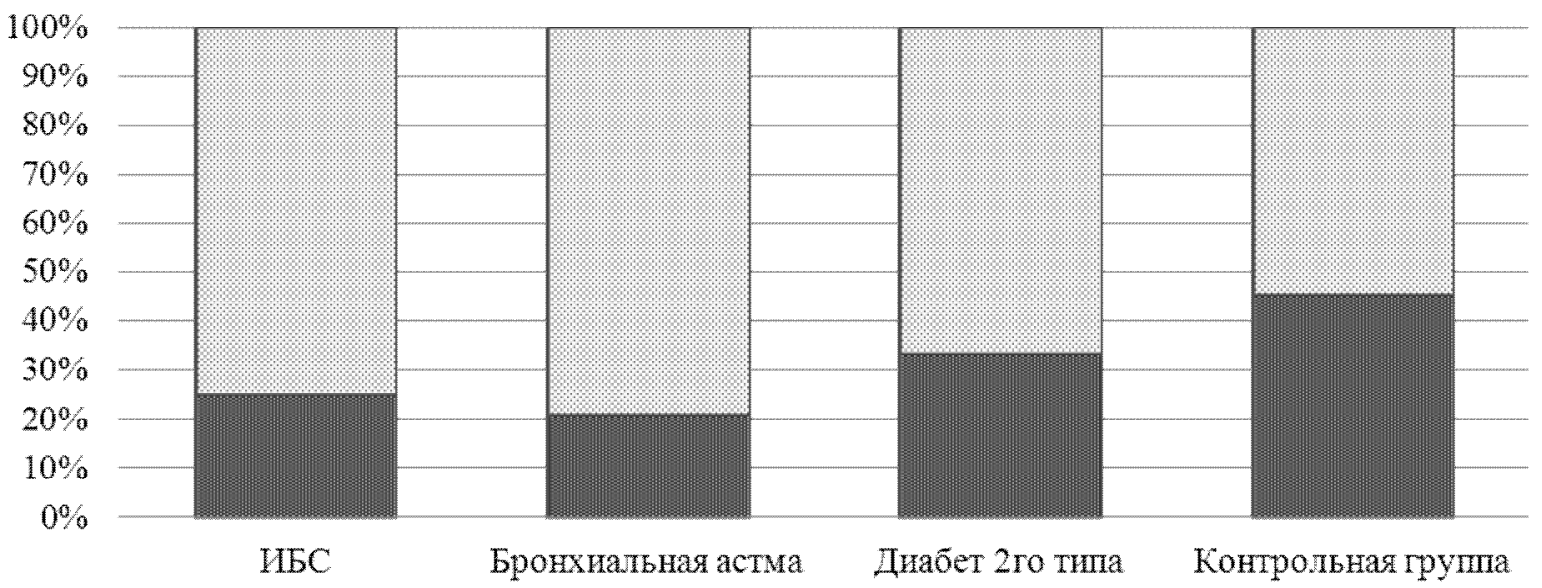

图 интернальность

Еэкстернальность

Рис. 2. Уровень общей интернальности личности.

Полученные данные позволяют определить наличие когнитивной переработки испытываемых интрацептивных ощущений, связанных с заболеванием, наиболее интенсивное изменение когнитивного компонента самосознания физического Я происходит при заболевании, симптомы которого связаны с высокой болезненностью, опасностью и в большей степени не могут быть купированы больным.

В результате исследования было выявлено, что в группах с ишемической болезнью сердца и бронхиальной астмой показатель рефлексивности носит в большей степени дезадаптивный характер, в группе с диабетом статистически значимых результатов не обнаружено (рис. 1).

В актуальной ситуации способность субъекта к соотнесению своих действий с ситуацией и их координации в соответствии с изменяющимися условиями и собственным состоянием находится на более низком уровне, что является отражением внутреннего кризиса, вызванного хроническим соматическим заболеванием. Поведенческими проявлениями и характеристиками этих изменений являются: степень обдумывания субъектом своей текущей деятельности и актуальной ситуации; то, насколько часто он прибегает к анализу происходящего; степень развернутости процессов принятия решения; склонность к самоанализу в конкретных жизненных ситуациях. Дезадаптивный уровень рефлексивности отражается на ретроспективном восприятии предпосылок, мотивов и причин произошедшего, содержании прошлого поведения, а также его результативных параметров и, в особенности, допущенных ошибок.

Данные исследования локуса контроля личности свидетельствуют о том, что в группах с хроническим соматическим заболеванием преобладает экстернальный уровень субъективного контроля (рис. 2). 
Из всех представленных групп наименьший средний показатель имеют группы с бронхиальной астмой и ишемической болезнью сердца. Таким образом, в группах с соматическим заболеванием преобладает чувство недостаточности субъективного контроля в актуальной ситуации. Больные не ощущают, что способны повлиять на течение заболевания и на его исход.

Средний уровень интернальности здоровья также значительно ниже в группах с соматическими заболеваниями (рис. 3).

Результаты позволяют судить о том, что в экспериментальных группах больные в большей степени возлагают ответственность за свое состояние на действия других людей, в данном случае врачей.

С возникновением заболевания теряется «прозрачность» тела [9], меняется привычный уклад жизни, приобретается новый телесный опыт. Под влиянием факторов рефлексивности и самодетерминации активируется гностический аспект сознания в отношении себя, своего тела, причин заболевания, перспектив и их возможностей. В результате происходит перестройка смысловой сферы (табл. 2).

Полученные результаты свидетельствуют о том, что показатель «цели в жизни» значительно снижен у исследуемых в группах с соматическим заболеванием, что указывает на фрустрацию жизненных стремлений в результате кризисной ситуации заболевания. Испытуемые с ИБС и бронхиальной астмой воспринимают свою жизнь в актуальной ситуации как менее эмоционально насыщенную, что выразилось в сниженных значениях показателя «процесс жизни». В группе больных диабетом статистически значимых различий не обнаружено. Данные параметра «результат жизни» свидетельствуют о том, что в группах испытуемых с диагнозами ИБС и диабет пройденный жизненный этап отмечается как менее удовлетворительный и осмысленный, чем в контрольной группе и группе с диагнозом бронхиальная астма.

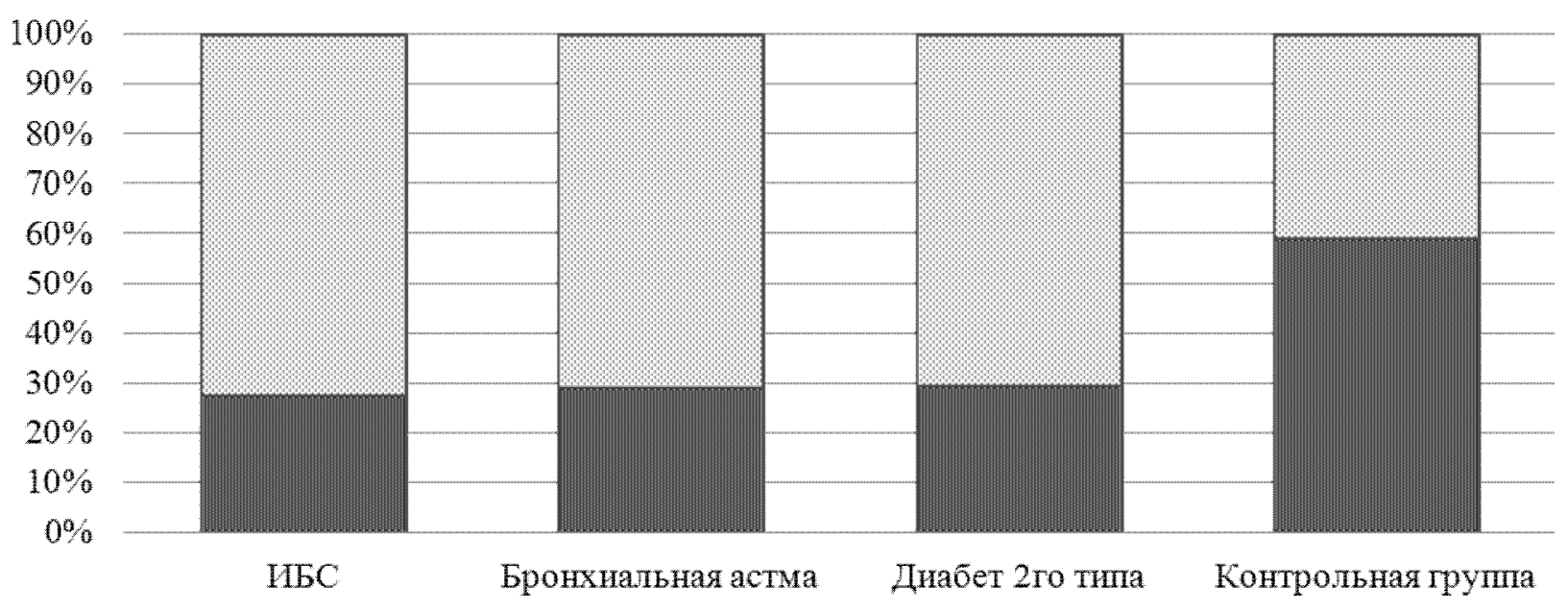

nнтернальность здоровья

圆 экстернальность здоровья

Рис. 3. Уровень интернальности личности в отношении здоровья.

Таблица 2

Показатели значимости различий компонентов ценностно-смысловой сферы у людей с хроническим соматическим заболеванием, в сравнении с людьми без соматических заболеваний

(U-критерий Mann-Whitney, $\mathrm{p}<0,05$ )

\begin{tabular}{|c|c|c|c|c|c|c|c|}
\hline \multirow{3}{*}{ Показатель } & \multirow{3}{*}{$\begin{array}{c}\begin{array}{c}\text { Контрольная группа } \\
\text { (здоровые) }\end{array} \\
\bar{x} \\
\end{array}$} & \multicolumn{6}{|c|}{ Группы исследования } \\
\hline & & \multicolumn{2}{|c|}{$\begin{array}{c}\text { ишемическая } \\
\text { болезнь сердца }\end{array}$} & \multicolumn{2}{|c|}{ бронхиальная астма } & \multicolumn{2}{|c|}{ диабет } \\
\hline & & p-level & $\bar{x}$ & p-level & $\bar{x}$ & p-level & $\bar{x}$ \\
\hline Цели в жизни & 33,5 & $0,004 * *$ & 28,5 & $0,032 *$ & 27,9 & $0,014 *$ & 31,7 \\
\hline Процесс жизни & 28,6 & $0,000 * *$ & 23,5 & $0,042 *$ & 25,1 & 0,538 & 28,6 \\
\hline Результат жизни & 26,2 & $0,001 * *$ & 24,5 & 0,148 & 26,1 & $0,045 *$ & 25,4 \\
\hline Локус контроля-Я & 22,1 & $\mathbf{0 , 0 0 0 * *}$ & 19,5 & 0,62 & 21,8 & $0,003 * *$ & 20,3 \\
\hline Локус контроля-жизнь & 29,1 & 0,460 & 28,8 & $0,024 *$ & 26,1 & 0,795 & 28,2 \\
\hline
\end{tabular}

Примечание: * $-\mathrm{p}<0,05 ; * *-\mathrm{p}<0,01$. 
Показатели значимости различий влияния образа тела на качество жизни больных с хроническим соматическим заболеванием

\begin{tabular}{|c|c|c|c|c|c|c|c|}
\hline \multirow{2}{*}{ Показатель } & \multirow{2}{*}{$\begin{array}{c}\text { Контрольная группа } \\
\text { (здоровые) }\end{array}$} & \multicolumn{5}{|c|}{ Группы исследования } \\
\cline { 3 - 8 } & $\bar{x}$ & ишемическая болезнь сердца & бронхиальная астма & \multicolumn{2}{|c|}{ диабет } \\
\hline & $\bar{x}$ & $\bar{x}$ & $\mathrm{p}-$ level & $\bar{x}$ & $\mathrm{p}$-level & $\bar{x}$ \\
\hline BIQLI & 2,30 & $\mathbf{0 , 0 0 0 * *}$ & 0,08 & $\mathbf{0 , 0 1 6 *}$ & 0,45 & $\mathbf{0 , 0 3 1}$ & 0,13 \\
\hline
\end{tabular}

Примечание: * $-\mathrm{p}<0,05 ; * *-\mathrm{p}<0,01$.

Низкие показатели по параметрам «локус контроля-Я» в группах с ИБС и диабетом демонстрирует преобладание представления о себе как о личности, не способной в полной мере контролировать свою жизнь в соответствии со своими целями. У испытуемых с бронхиальной астмой преобладает представление, что человеческая жизнь неподвластна сознательному контролю.

Анализ параметра оценки качества жизни позволяет сделать вывод о преобладании отрицательной оценки влияния образа тела на качество жизни при наличии хронического заболевания. В группах исследования преобладает представление о собственном теле в большей степени как о препятствии, отмечается большая неудовлетворенность собственным телом, зависимость самооценки от удовлетворенности собственным физическим состоянием, что находит отражение также в показателях жизненных целей, процесса жизни, саморефлексии телесного потенциала. Наиболее низкий показатель представлен в группе с ИБС, что может быть связано с высоким риском ухудшения состояния и чувством невозможности повлиять на это со стороны личности.

В результате исследования было выявлено, что телесный опыт хронического соматического заболевания связан с изменениями смысловой сферы личности и выражается в преобладании негативной оценки прошлого, настоящего и будущего, снижении значимости постановки жизненных целей. В группах с хроническими заболеваниями преобладает представление о себе как о личности, не способной в полной мере контролировать жизненную ситуацию в соответствии со своими целями и представлениями о ее смысле. Тело в большей степени воспринимается как препятствие. Наличие специфических симптомов заболевания, сопровождающихся телесными ощущениями, повлияло на интеграцию нового телесного опыта в Я-структуру, тем самым сформировав восприятие своего тела в большей степени как биологического фактора. Дезадаптивная взаимосвязь телесности и смыслового аспекта личности обусловлена блокированием рефлексивных процессов и повышением экстернализации уровня локуса контроля.

\section{ЛИТЕРАТУРА}

1. Бескова Д.А., Тхостов А.Ш. Телесность как пространственная структура // Междисциплинарные проблемы психологии телесности. - 2004 . С. 133-148.

2. Баранская Л.Т., Татаурова С.С. Методика исследования образа тела: учебное пособие Екатеринбург : Изд-во Урал. ун-та, 2009. - 82 с.

3. Василенко Т.Д. Психология телесности: процессуально-смысловой подход // Рос. психиатр. журн. - 2013. - № 4. - С. 49-55.

4. Василенко Т.Д. Жизненный путь личности: время и смысл человеческого бытия в норме и при соматической патологии - Курск: КГМУ, 2011. - 426 с.

5. Василюк Ф.Е. Психология переживания (анализ преодоления критических ситуаций) - М. : Изд-во Моск. ун-та, 1984. - 200 с.

6. Карпов А.B. Рефлексивность как психическое свойство и методика ее диагностики // Психол. журн. 2003. - Т. 24, № 5. - С. 45-57.

7. Леонтьев Д.А. Тест смысложизненных ориентации (СЖО). 2-е изд. - М. : Смысл, 2000. - 18 с.

8. Ложкин Г.В., Рождественский А.Ю. Феномен телесности в Я-структуре старшеклассников и содержании их жизненных проектов // Психол. журн. 2004. - Т. 25, № 3. - С. 27-33.

9. Менделевич В.Д. Клиническая и медицинская психология. - М. : МЕДпресс-информ, 2006. - 432 с.

10. Николаева В.В. Влияние хронической болезни на психику. - М. : Изд-во МГУ, 1987. - 16 с.

11. Реан А.А. Практическая психодиагностика личности: учеб. пособ. - СПб. : Изд-во СПб. ун-та, 2001.$224 \mathrm{c}$.

12. Соколова E.T., Николаева В.В. Особенности личности при пограничных расстройствах и соматических заболеваниях. - M. : SvR - Аргис, 1995. $352 \mathrm{c}$.

13. Тхостов А.Ш. Психология телесности. - М. : Смысл, 2002. - 287 с.

14. World Health Organization. Global status report on noncommunicable diseases 2014 [Электронный ресурс] // Сайт Всемирной организации здравоохранения. - 2014. - 280 р. - Режим доступа: http://apps.who.int/iris/handle/10665/148114, свободный (15.01.2016). 